\title{
The physiological consequences of changes in oxygen affinity in the red cell enzyme defects
}

\author{
E. R. HUEHNS
}

From the Department of Clinical Haematology, University College Hospital Medical School, London

Previous speakers have outlined the genetics and molecular pathology of the defects of enzymes of the glycolytic pathway. Recent work has shown that not only is glycolysis necessary for maintaining the integrity of the red cell and preventing the denaturation of haemoglobin by methaemoglobin formation or oxidation of the sulphydryl groups but it is intimately concerned with the control of oxygen affinity of the red cells. The action is mediated through the glycolytic intermediate 2,3 diphosphoglycerate (2,3-DPG). It has been known for a long time that 2,3-DPG occurs in the red cell in much higher concentration than in other cells, varying between 13.5 and $15.5 \mu \mathrm{mol} / \mathrm{g} \mathrm{Hb}(3.8-4.5 \mathrm{mmol} / \mathrm{l}$ packed cells). In 1967 two groups of workers showed independently that 2,3-DPG causes a marked lowering of the oxygen affinity of haemoglobin and changes in the level of 2,3-DPG in the red cell cause a change in the position of the red cell (fig 1) or whole blood oxygen dissociation curve, a rise of 2,3-DPG causing a fall in oxygen affinity. This modulating effect of 2,3-DPG on the oxygen affinity will alter the amount of oxygen released by each gram of haemoglobin as it passes

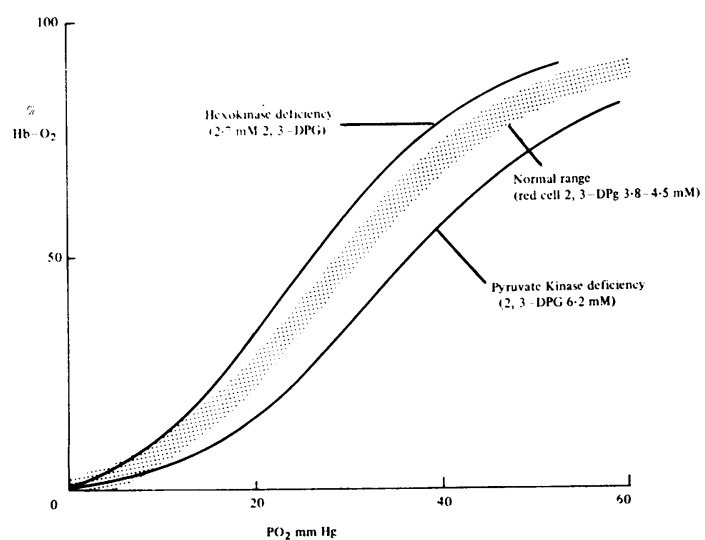

Fig 1 Oxygen dissociation curves of red cells with low, normal, and raised 2,3-DPG levels, isotonic bis tris buffer $\mathrm{pH} 7 \cdot 1$. It can be seen that between a $\mathrm{PO}_{2}$ of $100 \mathrm{mmHg}$ and $40 \mathrm{mmHg}$ the proportion of oxygen given off increases as the oxygen affinity falls. through the tissues at constant arterial and mean venous $\mathrm{PO}_{2}$. The main pathological conditions which alter the level of 2,3-DPG in the cell are (1) $\mathrm{pH}$, acidosis causing a reduction of 2,3-DPG while alkalosis increases it; (2) anaemia; and (3) the red cell enzyme defects. The detailed effects of these changes have been discussed elsewhere (for review see Oski and Gottlieb, 1971). In anaemia 2,3-DPG tends to rise and the oxygen affinity therefore falls allowing the tissues to extract more oxygen from the blood and thus partly compensating for the anaemia.

In the red cell enzyme defects the 2,3-DPG level is often altered leading to a change in oxygen affinity of the haemoglobin. In this case the change in oxygen affinity is primary and has certain important physiological consequences. The amount of oxygen available to the tissues depends on (1) the oxygen capacity of the blood, that is, the haemoglobin concentration; (2) the proportions of oxygen released as blood passes through the tissues which (at constant mean venous $\mathrm{PO}_{2}$ ) depends on the oxygen affinity (fig 1) and (3) on blood flow. The red cell mass and consequently the haemoglobin concentration are controlled by the secretion of erythropoietin and this in turn depends on the availability of oxygen to the tissues but appears to be independent of blood flow to the tissues. Any primary change in oxygen affinity would therefore affect erythropoietin production and the red cell mass. The largest group of patients who have a primary change in the oxygen affinity of their red cells are of course those with the abnormal haemoglobins. In patients with abnormal haemoglobins with a high oxygen affinity the red cell mass is expanded by action of the erythropoietin mechanism and this is confirmed by the demonstration that when these patients are bled to reduce the haemoglobin level to normal erythropoietin excretion increases and the red cell mass again expands (Adamson, Parer, Stamatoyannopoulos, and Heinenberg, 1969). Eventually the haemoglobin level is such that oxygen delivery to the tissues is virtually normal.

In chronic haemolysis the situation is similar and is again best illustrated by the abnormal haemo- 


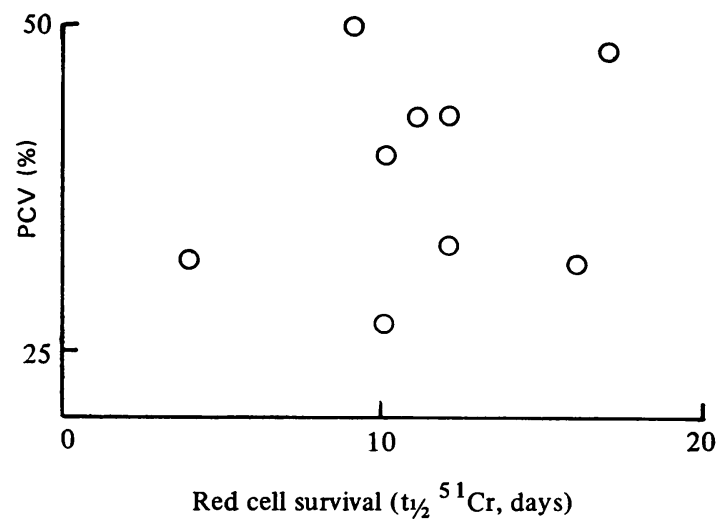

Fig 2 Lack of correlation between red cell survival and packed cell volume for unstable haemoglobin diseases.

globins. In these chronic conditions it might be argued that when equilibrium ie, destruction equals production, is reached the degree of anaemia would be related to the extent to which red cell life is shortened. However, examination of the available data (fig 2) shows that, although this may be involved to some degree, the level of anaemia found is mainly determined by other factors. The same argument that has been applied to erythrocytosis above can also be used when haemolysis is present. This implies that when there is a high oxygen affinity and the relative availability of oxygen per gram of haemoglobin is low the marrow drive will be greater than when there is a low oxygen affinity with consequent greater release of oxygen from each gram of haemoglobin. This hypothesis suggests that a high oxygen affinity will be associated with a high haemoglobin, while with a low oxygen affinity the haemoglobin will be low and this is confirmed by the data in fig 3 (Huehns and Bellingham, 1969). However, the equilibrium haemoglobin level achieved with a normal oxygen affinity is lower than when there is no haemolysis. These arguments of course do not apply only to the abnormal haemoglobins but also to other chronic haemolytic anaemias.

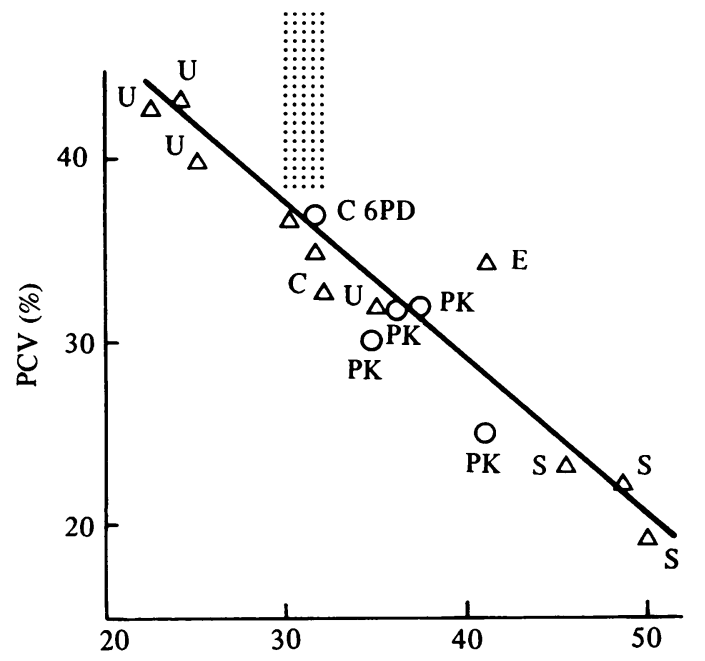

Partial pressure of oxygen at $1 / 2$ saturation of haemoglobin $\left(P_{50}\right)(\mathrm{mm} \mathrm{Hg})$

Fig 3 Correlation between the oxygen affinity of red cells with the PVC in patients with chronic haemolytic anaemias in the steady state due to abnormal haemoglobins $(\triangle)$ and enzyme deficiencies $(\bigcirc)$. U, unstable haemoglobins, S, sickle-cell anaemia, C, haemoglobin$C$ disease, E, haemoglobin-E disease, $\mathrm{PK}$, pyruvatekinase deficiency, G-6-PD, glucose-6-phosphate dehydrogenase deficiency. Normal adults. The oxygen affinity was determined on washed red cells suspended in an isotonic phosphate buffer, $p H 7 \cdot 1$, at $37^{\circ} \mathrm{C}$.

In the erythrocyte enzyme defects the level of 2,3-DPG varies according to where in the glycolytic pathway the defect is (table I). In general a defect below 2,3-DPG or affecting phosphoglycerate kinase (PGK) leads to a high level of 2,3-DPG and a low oxygen affinity results. Clinically this leads to a low haemoglobin level. In practice most of these patients have pyruvate kinase (PK) deficiency already discussed.

In defects of the pentose phosphate pathway a normal 2,3-DPG is found and in patients with

\begin{tabular}{|c|c|c|c|}
\hline Defective Enzyme & $2,3-D P G$ & Oxgen Affinity & Degree of Anaemia \\
\hline Hexokinase & Low & Raised & None \\
\hline $\begin{array}{l}\text { Glucose-6-phosphate dehydrogenase with chronic } \\
\text { haemolysis }\end{array}$ & Normal & Normal & Mild \\
\hline Triose phosphate isomerase & Normal & - & $\begin{array}{l}\text { Mild (neurological } \\
\text { syndrome) }\end{array}$ \\
\hline Diphosphoglycerate (DPG) mutase & Low & Raised & None \\
\hline Phosphoglycerate kinase & High & Low & Severe \\
\hline Pyruvate kinase & High & Low & Severe \\
\hline Hereditary spherocytosis & Low & Raised & Very mild or none \\
\hline
\end{tabular}

Table I 2,3-DPG, oxygen affinity changes, and degree of anaemia in various red cell enzyme defects 
chronic haemolysis due to G-6-PD deficiency haemoglobin is only moderately reduced.

In defects of enzymes before 2,3-DPG, 2,3-DPG is often low (see table I). This leads to a raised oxygen affinity and a better marrow drive and there is either completely compensated haemolysis or only mild anaemia. In hereditary spherocytosis 2,3-DPG is also often low and a raised oxygen affinity with compensated haemolysis is the clinical picture.

The finding that the packed cell volume, ie, redcell mass, is closely geared to the oxygen affinity of the red cells means that in haemolytic diseases in the steady state the oxygen delivery to the tissues is the same regardless of whether there is a high or low haemoglobin concentration, and this conclusion accounts for the normal development of many of these patients and the mild nature of the disease even when the haemoglobin is low. However, it should be noted that although this is undoubtedly true in the uncomplicated disease, in conditions of stress, such as strenuous exercise, increased anaemia etc, when the tissue oxygen tensions tend to be lower than normal, patients with a high oxygen affinity and a high PCV are at a distinct advantage compared with those with a low oxygen affinity and a low packed cell volume. This results in part from the position and shape of the oxygen dissociation curve as well as from the higher capacity of the blood of patients with a high packed cell volume. Another advantage of a high oxygen affinity is that the arterial oxygen content is protected against any fall in arterial $\mathbf{P O}_{2}$ due to, for example, respiratory disease.

Thus the recent understanding of the function of 2,3-DPG in red cells together with the elucidation of the effect of changes in oxygen affinity on erythropoietin control of red cell production explains the clinical picture and the different degrees of anaemia found with various red cell enzyme defects.

\section{References}

Adamson, J. W., Parer, J. T., and Stamatoyannopoulos, G., (1969). Erythrocytosis associated with hemoglobin Rainier: oxygen equilibria and marrow regulation. J. clin. Invest., 48, 1376-1386.

Huehns, E. R., and Bellingham, A. J. (1969). Diseases of function and stability of haemoglobin. Brit. J. Haemat., 17, 1-10.

Oski, F. A., and Gottlieb, A. J. (1971). The interrelationships between red blood cell metabolites, hemoglobin, and the oxygenequilibrium curve. Progr. Hemat., 7, 33-67. 